\title{
Effects of Predamaged Level on Confined HSC Columns
}

\author{
Chau-Khun $\mathrm{Ma}^{1, *}$, Sofrie Siew-Yung Chin ${ }^{1}$, Nazirah Mohammad Apandi ${ }^{1}$, Abdullah \\ Zawawi Awang ${ }^{1}$, and Wahid Omar $^{2}$ \\ ${ }^{1}$ Department of Structure and Materials, Faculty of Civil Engineering, Universiti Teknologi Malaysia, \\ 81310, Johor Bahru, Malaysia \\ ${ }^{2}$ Office of Chancellery, Universiti Teknologi Malaysia, 81310, Johor Bahru, Malaysia
}

\begin{abstract}
In the design of repair works for damaged concrete, an accurate and representative stress-strain model is of important. The stress-strain model for damaged high strength concrete (HSC) repaired with posttensioning steel straps confinement yet available, although the confining method has been proven to be effective in improving the performance of non-damaged HSC. A series of experimental test was carried out to investigate the stress-strain relationships of such concrete. A total of 24 HSC cylinders were compressed until certain damaged levels, then repaired by using steel straps. Two important parameters have been identified to have significant effects on the stress-strain relationship of such repaired concrete, namely the confining volumetric ratio and damaged levels. These parameters were incorporated into the development of stressstrain model, which later was shown to correlate well with the experimental results. This paper also has evidenced that existing stressstrain models of damaged concrete are not suitable to be directly applied to the design of repair works using post-tensioning steel straps confinement that produce external lateral stress on damaged columns before subsequent loading applied.
\end{abstract}

\section{Introduction}

When a concrete structure was damaged due to major events such as earthquakes, blast or impact, its integrity has been compromised and it can collapse anytime if no immediate actions were taken to restore its capacity [1-6]. An engineer can choose to either replace the affected structure members with new members, demolish the structure for rebuild or emergency repair. Due to the economic consideration, mostly the latter will be chosen as it requires less time, cheaper, easier and most importantly, it is highly effective. Past research works have proven that rapid repairing using confinement is effective in restoring the original strength of the concrete columns [7-10]. Besides, it was also reported that the confinement restored the ductility of damaged concrete as well [10-16]. Despite the effectiveness, the utilisation of such repairing method in the construction industry is particularly limited.

* Corresponding author: machaukhun@gmail.com 


\section{Load-induced damaged specimens}

A total of 24 HSC cylinders with diameter of $100 \mathrm{~mm}$ and height of $200 \mathrm{~mm}$ were prepared in this study. The targeted concrete compressive strength is $50 \mathrm{MPa}$ with mix proportions as shown in Table 1. Another 9 corresponding concrete cubes were prepared alongside with the specimens for the determination of concrete compressive strength. Based on the analysis of the cube tests, the average concrete compressive strength is $50.27 \mathrm{MPa}$ with standard deviation of $4.6 \mathrm{MPa}$ at the age of 28 days after curing. The specimens were then pre-loaded to damage the cylinders to simulate the situations where concrete were damaged at $0 \%, 50 \%, 100 \%$ and $-50 \%$ (load reduction of $50 \%$ at post-peak region) of axial load capacity. Pre-damage level was determined to justify the behaviour of columns under different confinement configuration. Selected damage level would give better understanding on the columns response in term of strength and ultimate strain. However, the $-50 \%$ of pre-damaged load was unsuccessful to be achieved as most of the specimens failed immediately after the ultimate load has been reached. Hence, the $-50 \%$ of predamaged levels here also represent any failure load achieved after the ultimate load even it was less than $50 \%$. The details of the specimens are tabulated in Table 2.

Table 1. Mix portions of $1 \mathrm{~m}^{3}$ concrete

\begin{tabular}{|c|c|c|}
\hline Material & Type & Quantity \\
\hline OPC $(\mathrm{kg})$ & Portland & 409 \\
\hline Sand $(\mathrm{kg})$ & River sand & 806 \\
\hline Aggregate $(\mathrm{kg})$ & $10 \mathrm{~mm}$ & 1025 \\
\hline Superplasticizer $(l)$ & Glenium C380 & 1.6 \\
\hline Water $(\mathrm{kg})$ & Tap water & 162 \\
\hline
\end{tabular}

Table 2a. Details of tested specimens

\begin{tabular}{|c|c|c|c|c|c|c|}
\hline Specimen ID & $\begin{array}{c}\text { Steel } \\
\text { Straps } \\
\text { layer }\end{array}$ & $\begin{array}{c}\text { Spaci } \\
\text { ng } \\
(\mathbf{m m})\end{array}$ & $\begin{array}{c}\text { Pre- } \\
\text { damaged } \\
\text { level (\%) }\end{array}$ & $\begin{array}{l}\text { Volumetric } \\
\text { Ratio }\left(p_{v}\right)\end{array}$ & $\begin{array}{l}\text { Ultimate } \\
\text { load }(\mathrm{kN})\end{array}$ & $\begin{array}{l}\text { Ultimate } \\
\text { displacem } \\
\text { ent ( } \mathrm{mm})\end{array}$ \\
\hline C50-0-0 (0) & - & - & - & 0 & 438.3 & 0.40 \\
\hline C50-30-1 (0) & 1 & 30 & - & 0.1 & 394.3 & 0.60 \\
\hline C50-10-1 (0) & 1 & 10 & - & 0.15 & 420.2 & 0.63 \\
\hline C50-30-2 (0) & 2 & 30 & - & 0.2 & 540.4 & 0.88 \\
\hline C50-30-3 (0) & 3 & 30 & - & 0.3 & 533.3 & 1.40 \\
\hline C50-10-2 (0) & 2 & 10 & - & 0.3 & 582.8 & 2.38 \\
\hline C50-0-0 $(+50)$ & - & - & +50 & 0 & 162.6 & 0.46 \\
\hline C50-30-1 (+50) & 1 & 30 & +50 & 0.1 & 421.1 & 0.69 \\
\hline C50-10-1 (+50) & 1 & 10 & +50 & 0.15 & 420.6 & 0.85 \\
\hline C50-30-2 (+50) & 2 & 30 & +50 & 0.2 & 458.7 & 1.50 \\
\hline C50-30-3 (+50) & 3 & 30 & +50 & 0.3 & 521.5 & 1.63 \\
\hline C50-10-2 (+50) & 2 & 10 & +50 & 0.3 & 563.9 & 2.64 \\
\hline C50-0-0 $(+100)$ & - & - & +100 & 0 & 162.6 & 0.52 \\
\hline C50-30-1 (+100) & 1 & 30 & +100 & 0.1 & 286.7 & 0.76 \\
\hline C50-10-1 (+100) & 1 & 10 & +100 & 0.15 & 415.5 & 0.90 \\
\hline C50-30-2 (+100) & 2 & 30 & +100 & 0.2 & 423.4 & 1.24 \\
\hline C50-30-3 (+100) & 3 & 30 & +100 & 0.3 & 512.9 & 1.55 \\
\hline C50-10-2 (+100) & 2 & 10 & +100 & 0.3 & 553.8 & 2.71 \\
\hline C50-0-0 (-50) & - & - & -50 & 0 & 149.2 & 0.61 \\
\hline C50-30-1 (-50) & 1 & 30 & -50 & 0.1 & 222.3 & 0.75 \\
\hline $\mathrm{C} 50-10-1(-50)$ & 1 & 10 & -50 & 0.15 & 366.0 & 1.61 \\
\hline
\end{tabular}


Table 2b. Details of tested specimens

\begin{tabular}{|c|c|c|c|c|c|c|}
\hline Specimen ID & $\begin{array}{c}\text { Steel } \\
\text { Straps } \\
\text { layer }\end{array}$ & $\begin{array}{c}\text { Spaci } \\
\text { ng } \\
(\mathrm{mm})\end{array}$ & $\begin{array}{c}\text { Pre- } \\
\text { damaged } \\
\text { level }(\%)\end{array}$ & $\begin{array}{c}\text { Volumetric } \\
\text { Ratio }\left(p_{v}\right)\end{array}$ & $\begin{array}{l}\text { Ultimate } \\
\text { load }(k N)\end{array}$ & $\begin{array}{l}\text { Ultimate } \\
\text { displacem } \\
\text { ent }(\mathrm{mm})\end{array}$ \\
\hline C50-30-2 (-50) & 2 & 30 & -50 & 0.2 & 328.3 & 2.42 \\
\hline C50-30-3 (-50) & 3 & 30 & -50 & 0.3 & 323.6 & 2.12 \\
\hline C50-10-2 (-50) & 2 & 10 & -50 & 0.3 & 404.5 & 2.95 \\
\hline
\end{tabular}

\section{Steel strapping works}

In this study, the spacing between the steel straps were fixed into $10 \mathrm{~mm}$ (closest spacing) and $30 \mathrm{~mm}$. The spacing were designed not to more than $60 \mathrm{~mm}$ (center to center). The specimens were confined with 1, 2 and 3 layers steel straps. Confined specimens are shown in Fig. 1. All confined specimens were confined from end to end to prevent concrete crushing near the load platens. Steel strap were install after pre-damaged load to investigate the effectiveness of confinement in repairing works.

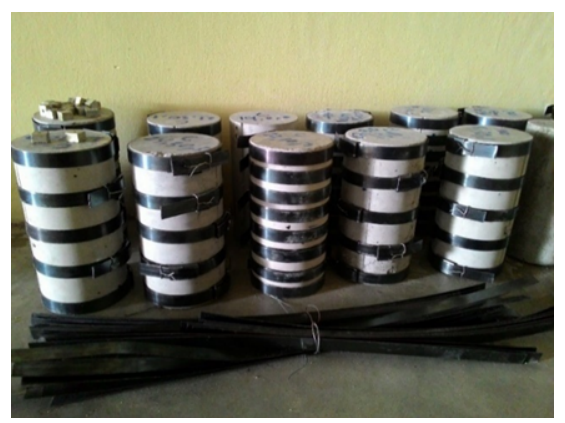

Fig. 1. Steel strapping confinement

\section{Loading procedure}

The compressive strength of the concrete was determined by uniaxial compression test using 'Tinius Olsen' compression machine that has a maximum load capacity of 2,500 kN. All tests were conducted in the Laboratory of Structure and Materials in Universiti Teknologi Malaysia (UTM). The loading is displacement controlled with constant rate of $0.01 \mathrm{~mm} / \mathrm{s}$ for all specimens (Fig. 2).

During the test, the axial load and vertical strains were recorded by an automatic data acquisition through data logger to monitor the stress-strain behaviour of the specimens. The variations of axial strains of the specimen were measured by two $50 \mathrm{~mm}$ omega strain gauges attached at both sides of the specimen. The variations in readings between the two omega strain gauges were monitored closely and the testing was stopped immediately in case the variations exceeding $10 \%$, indicating the specimen was not aligned in the center of the platen. The specimen was then re-positioned and centered again until the variation is less than $10 \%$. This initial testing is very important to avoid any unalign setup which may produce unreliable data. The axial load selected in the pre-testing is choosen to not affect the intergritiy of the specimen. The specimen was monotonically loaded until the specimen failed. 


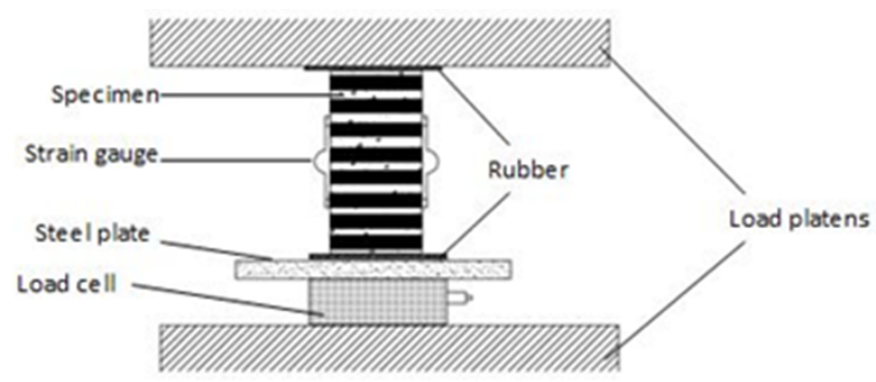

Fig. 2. Compression test setup

\section{Infliction of damage}

The uniaxial compression testing of concrete cylinders was inflicted by pre-compression of the cylinders to a certain degree. The pre-damaged to the concrete cylinders to a stress that equals a certain percentage of the peak strength $0,+50,100,-50 \%$, termed as damage level, as shown in Fig. 3. The positive sign indicates a pre-compression load on the ascending branch (before achieving peak strength), whereas the negative sign denotes a load on the descending branch.

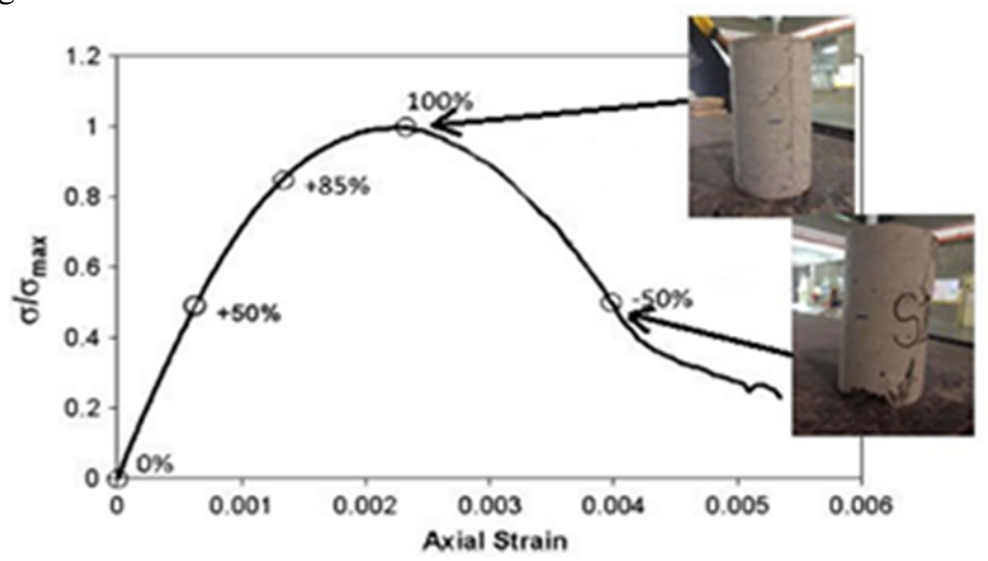

Fig. 3. Definition of damage level

For negative damage levels, the final applied load was calculated and monitored during a test as the actual peak load (observed when the applied load just falls into the descending branch) multiplied by the prescribed percentage. For positive damage levels, the peak load was estimated from the mean peak loads of the specimens in the group that had negative damage levels that had been tested first.

Because of the fast drop in load at the descending branch, the loading rates were carefully examined and selected by testing so that the applied load could be stopped at prescribed loads with reasonable accuracy. For this study, the loading rate will be fixed at $0.01 \mathrm{~mm} / \mathrm{s}$. When the pre-damaged load reached a prescribed value, the cylinder was unloaded immediately.

\section{Pre-damaged effects on confined HSC columns}

The effects of damaged degrees to strength and displacement are as shown in Fig. 4 and Fig. 5 Apparently, a descending relationship exists between ultimate strength and damaged 
degree. Drastic drop was observed for group $\rho_{\mathrm{v}}=0$ (unconfined columns). The slope of the trendlines become gentler with the increase of $\rho_{\mathrm{v}}$. Unexpected large scatter was observed in the relationships of strain versus damaged degree indicating the effect of damaged degree in strain is comparatively negligible. This finding was similar with those reported by $\mathrm{Wu}$ et al. in the investigation of repaired concrete using CFRP jacketing [2]. However, no detail explanation was given in their report. Force - displacement relationship of specimen shown in Fig. 5 which represent the effects of various damage level on columns performance after confinement. From the results, damage level at 50\% and 100\% almost response similary but higher damage level gives lower strength recovery. Volumetric ratio demand of damage columns represented in Fig. 6 that shown higher volumetric ratio is required for undamaged column compared to damaged column which proved that steel strap confinement technique is effective in reducing dilation of concrete column under loading. At damage level of $50 \%$ and $100 \%$, equal demand for volumetric ratio is observed.

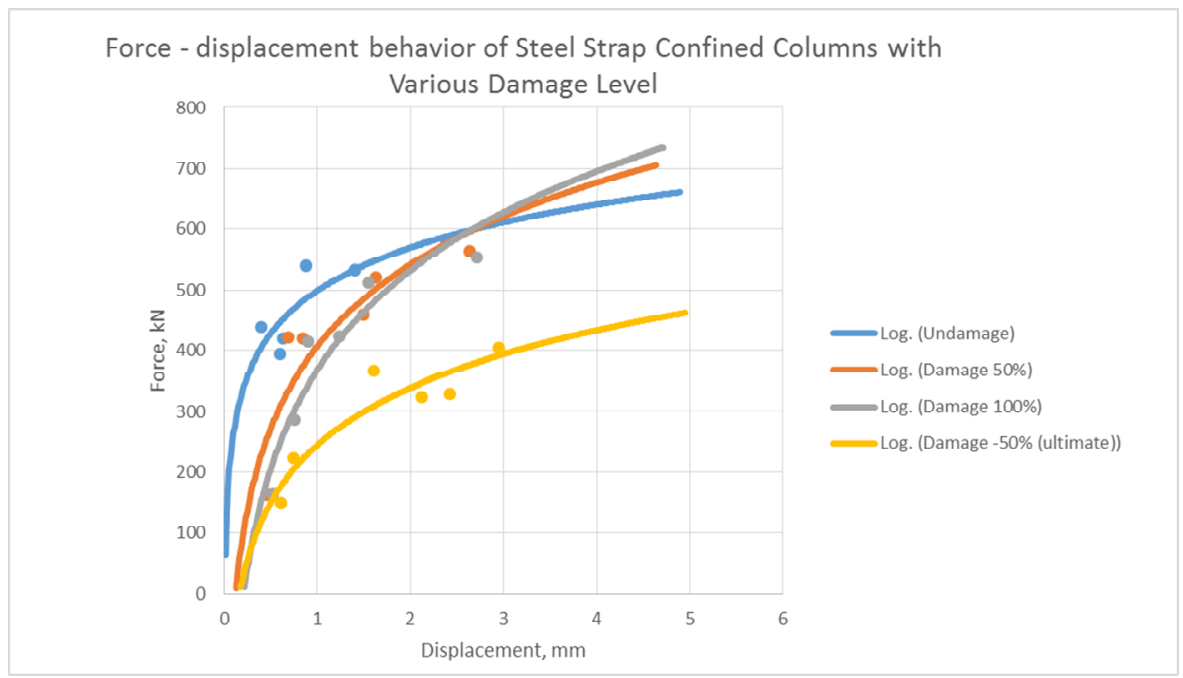

Fig. 4. Force - displacement relationship of repaired columns with various damage levels

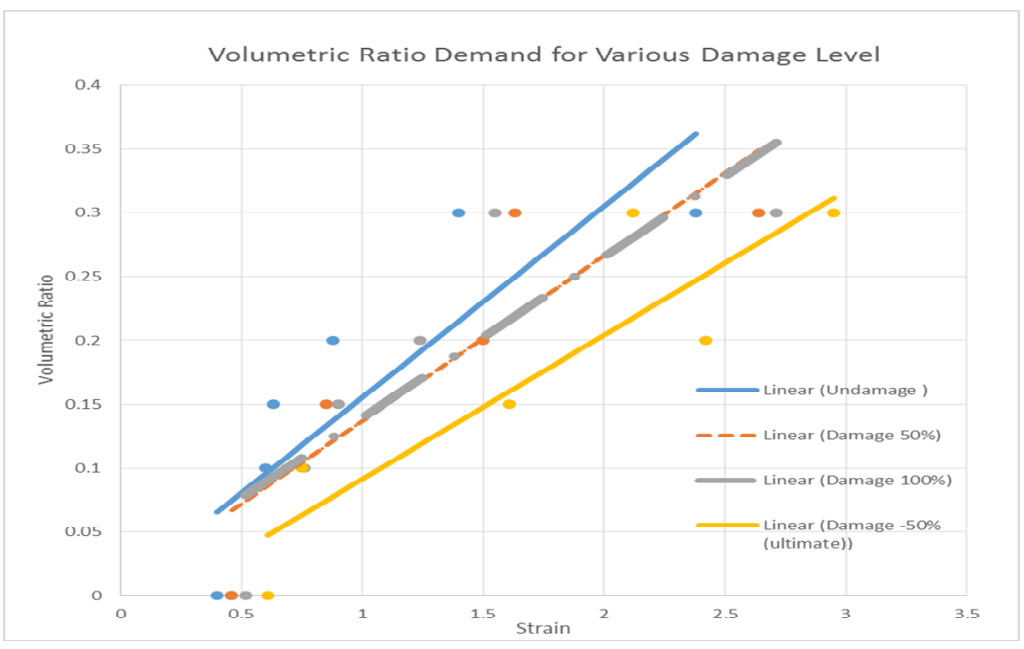

Fig. 5. Volumetric ratio demand for various damage level 


\section{Effects of pre-damaged level of repaired high strength concrete column on deformability}

From Fig. 6, with the aid of confinement from steel strap, the deformability of repaired HSC improve with optimum spacing and confinement layer. The optimum spacing for higher deformability of repaired HSC column are $10 \mathrm{~mm}$ and 2 layer of steel strap. The deformability can be reflected from stress - strain curve of repaired HSC specimens. For 1 and 2 layer of steel strap confinement, the available spacing are $10 \mathrm{~mm}$ and $30 \mathrm{~mm}$ respectively whereas for 3 layer of steel strap confinement only available for $30 \mathrm{~mm}$ of spacing. The different result from each category are due to effects of pre-damaged level. It is worth noting that under same volumetric ratio, closer spacing $(10 \mathrm{~mm})$ produce higher ultimate strain of $70 \%, 61 \%, 75 \%$ and $39 \%$ for damage level at $0 \%, 50 \%, 100 \%$ and $-50 \%$ respectively.

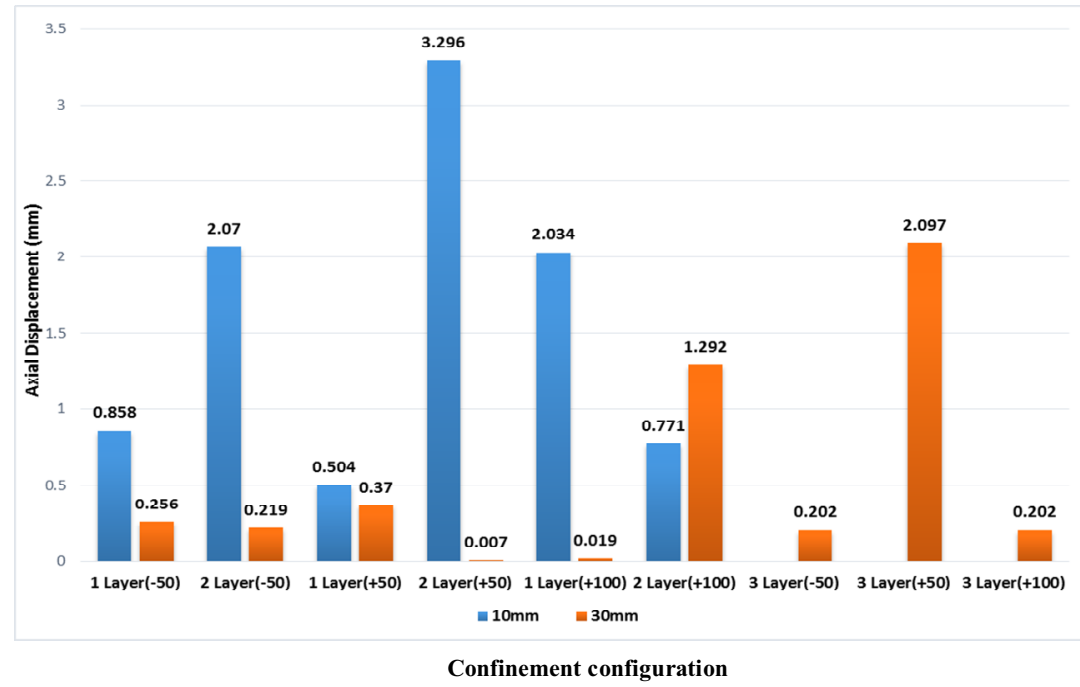

Fig. 6. Deformability of Repaired HSC Columns

\section{Summary and conclusion}

A series of experimental and analytical studies were performed to investigate the stressstrain of repaired HSC using post-tensioning steel straps confinement. It was evidenced that the pre-damaged degree is an important factor and needed to be considered in estimating the ultimate strength and strain of repaired concrete. In general, it was found that the ultimate strength reduced with the increase of concrete damaged degree. Whilst the ultimate strain increased with damaged degree. Under same volumetric ratio, closer spacing provide better ultimate strain for repaired concrete columns shows the desired for confinement of damage column. Equal volumetric ratio found for damage level at $50 \%$ and $100 \%$ strength. Force - displacement relationship at each damage level are different but close behaviour observed at $50 \%$ and $100 \%$ damage level.

This work was funded by Fundamental Research Grant Scheme (FRGS) from Ministry of Higher Education, Malaysia [R.J130000.7822.4F826]. The first author would like to acknowledge that the undergraduate students Amirul Radzi, Melvay Allens and Muhammad Fadhli undertook the tests as their final year projects supervised by the first author. 


\section{References}

[1] A.G. Tsonos, Effectiveness of CFRP-jackets and RC-jackets in post-earthquake and pre-earthquake retrofitting of beam-column subassemblages, Engineering Structures, 30(3), 777-793, (2008)

[2] Y.F. Wu, Y.Yun, Y. Wei, and Y. Zhou, Effect of predamage on the stress-strain relationship of confined concrete under monotonic loading, J. of Structural Engineering, 140(12), 04014093, (2014)

[3] Y.W. Zhou, X.M. Liu, L.L. Sui, F. Xing, and H.J. Zhou, Stress-strain model for fibre reinforced polymer confined load-induced damaged concrete, Materials Research Innovations, 19(sup6), S6-125, (2015)

[4] M. Panjehpour, N. Farzadnia, R. Demirboga, and Ali, A.A.A. Behavior of highstrength concrete cylinders repaired with CFRP sheets, J. of Civil Engineering and Management, 22(1), 56-64, (2016)

[5] A. Peled, Confinement of damaged and nondamaged structural concrete with FRP and TRC sleeves, J. of Composites for Construction, 11(5), 514-522, (2007)

[6] A. Ilki, O. Peker, E. Karamuk, C. Demir, and N. Kumbasar, FRP retrofit of low and medium strength circular and rectangular reinforced concrete columns, J. of Materials in Civil Engineering, 20(2), 169-188, (2008)

[7] D.S. Gu, G. Wu, Z.S. Wu, and Y.F. Wu, Confinement effectiveness of FRP in retrofitting circular concrete columns under simulated seismic load, J. of Composites for Construction, 14(5), 531-540, (2010)

[8] R.D. Iacobucci, S.A. Sheikh, and O. Bayrak, Retrofit of square concrete columns with carbon fiber-reinforced polymer for seismic resistance, ACI Structural J., 100(6), 785794,(2003)

[9] C.K. Ma, A.Z. Awang, and W. Omar, New theoretical model for SSTT- confined HSC columns, Magazine of Concrete Research, 66(13), 674-684, (2014)

[10]C.K. Ma, A.Z. Awang, R. Garcia, W. Omar, K. Pilakoutas, and M. Azimi, Nominal curvature design of circular HSC columns confined with post-tensioned steel straps, Structures, 7, 25-32,(2016)

[11]C.K. Ma, A.Z. Awang, W. Omar, M. Liang, S-W. Jaw, and M. Azimi, Flexural capacity enhancement of rectangular high-strength concrete columns confined with post-tensioned steel straps: experimental investigation and analytical modelling, Structural Concrete, 17(4), 668-676, (2016).

[12]C.K. Ma, A.Z. Awang, R. Garcia, W. Omar, and K. Pilakoutas, Behaviour of over-reinforced high-strength concrete beams confined with post-tensioned steel straps-an experimental investigation, Structural Concrete, 17(5), 768-777, (2016)

[13]C.K. Ma, A.Z. Awang and W. Omar, Slenderness effect and upper-bound slenderness limit of SSTT-confined HSC column, Int. J. of Structural Engineering, 5(3), 279-286, (2014)

[14]C.K. Ma, A.Z. Awang, and W. Omar, Flexural ductility design of confined highstrength concrete columns: Theoretical modelling, Measurement, 78, 42-48, (2016)

[15]D.E. Lehman, S.E. Gookin, A.M. Nacamuli and J.P. Moehle, Repair of earthquakedamaged bridge columns, ACI Structural J., 98(3), 233-238, (2001)

[16]D.R. Stoppenhagen, J.O. Jirsa, and L.A. Wyllie, Seismic repair and strengthening of a severely damaged concrete frame, ACI Structural J., 92(2), 177-187.9.(1995) 